\title{
Cómo la Teoría de la Especificidad cambia la práctica clínica ${ }^{i}$ Howard A. Bacali con Lucyann Carlton ${ }^{\text {iii }}$ Los Ángeles, CA, USA
}

Presentamos dos ejemplos clínicos, ofrecidos por Lucyann Carlton, que ilustran cómo la Teoría de la Especificidad cambia nuestra práctica clínica. Los ejemplos incluyen viñetas de dos análisis distintos; uno en el que la autora ${ }^{1}$ es la analizada y otro en el que es (ella) la analista. El primer análisis se realizó guiado por la teoría psicoanalítica clásica y el segundo, por la teoría de la especificidad. Las viñetas subrayan la diferencia teórica esencial entre los dos tipos de teoría - la teoría de la estructura asociada con la respuesta "conocida", y la teoría del proceso, que está determinada por una posición situada desde lo "no conocido". También ilustran la diferencia a nivel clínico que se manifiesta en el desplazamiento desde la respuesta basada en principios establecidos, a la postura de ser consciente del potencial para la terapia, teniendo en cuenta el significado de cómo puede estar la terapeuta dentro del contexto específico del tratamiento con un paciente particular.

\section{Palabras clave: Teoría de la Especificidad, Psicoanálisis Clásico, Técnica, Proceso terapéutico}

Here are two clinical examples, offered by Lucyann Carlton, which illustrate how Specificity Theory changes our practice. The examples comprise vignettes from two different analyses, one in which the author was the analysand and one in which she was the analyst. The first analysis was guided by classical psychoanalytic theory and the second by Specificity Theory. The vignettes draw attention to the essential theoretic difference between the two types of theory - structure theory, associated with "known" response, and process theory, which determines a position of not-knowing. They also illustrate the clinical difference as we note the shift from responding on the basis of established tenets to awareness of the potential for the therapy when the analyst considers the significance of how she can be within the specific context of treatment with the particular patient.

Key Words: Specificity Theory, Classical Psychoanalysis, Technique, Therapeutic Process English Title: How Specificity Theory Changes Clinical Practice

\section{Cita bibliográfica / Reference citation:}

Bacal, H.A. y Carlton, L. (2017). Cómo la teoría de la especificidad cambia la práctica clínica. Clínica e Investigación Relacional, 11 (2): 232-245. [ISSN 1988-2939] [Recuperado de www.ceir.info ] DOI: 10.21110/19882939.2017.110202

\footnotetext{
i Extracto de llustraciones clínicas del capítulo 3 de la obra: El poder de la especificidad en la psicoterapia: cuándo la terapia funciona - y cuando no. Howard Bacal (2011). Lanham, MD: Jason Aronson. Traducción castellana de María Hernández Gazquez, revisada por Alejandro Ávila. Texto usado en el Seminario Clínico realizado en Madrid, en Ágora Relacional / Instituto de Psicoterapia Relacional, el 6 de Mayo de 2017 para el Programa de Formación en Psicoterapia Psicoanalítica Relacional.

ii HOWARD A. BACAL, M.D., es Psicoanalista y Psicoterapeuta (Los Ángeles, CA, USA). Analista Didacta y Supervisor del Institute of Contemporary Psychoanalysis, Los Ángeles; Analista Didacta y Supervisor del New Center for Psychoanalysis, Los Ángeles; Analista Didacta y Supervisor del Institute for the Psychoanalytic Study of Subjectivity, New York. Ha presidido las conferencias internacionales anuales de la Psicología del Self de 1984, 1993, 2001, 2004, 2007 y es miembro del Consejo Asesor de la IAPSP. Ha publicado muy numerosos y destacados trabajos, entre ellos sus libros: Optimal Responsiveness. How Therapist heal their patients ( $\mathrm{H}$. Bacal, Ed., Jason Aronson, 1998) y The Power of Specificity in Psychotherapy. When therapy works and when it doesn't (H. Bacal con L. Carlton, Jason Aronson, 2011).

iii LUCYANN CARLTON, PsyD, JD, es analista didacta y supervisora en el Institute of Contemporary Psychoanalysis, Los Ángeles y mantiene práctica privada en Irvine, California.
}

CeIR Vol. 11 (2) - Junio 2017 ISSN 1988-2939 - www.ceir.info

(c) Derechos reservados/Copyright de Clínica e investigación Relacional y los autores. Prohibida la reproducción total o parcial sin autorización expresa. Este material es para uso científico y profesional exclusivamente y puede contener información clínica sensible. Los editores no se responsabilizan de los contenidos de los autores. Dirigir las consultas sobre derechos y autorizaciones a ceir@psicoterapiarelacional.es 


\section{La práctica que prioriza la tradicional Teoría de la estructura}

Cuando me reuní por primera vez con mi analista, nos sentamos cara a cara mientras ella evaluaba si yo era o no analizable. Le relaté mis dificultades en ese momento, mi historia familia y mi desarrollo personal. Ella compartió conmigo que tenía dudas sobre mí. Yo parecía ser alguien que le gustaba ser "la capitana de su propio barco". "Esto no es un buen presagio para el análisis," opinó mi analista. Sin embargo, sugirió unos meses de prueba. Estableció unas normas para nuestro compromiso. "Cada vez que entres, te tumbarás en el diván. Empezarás a hablar, diciendo lo primero que venga a tu mente. Yo estaré callada. Escucharé y únicamente hablaré cuando tenga algo que decir". Y así comenzó nuestra odisea.

No podía comprender cómo el supuesto de querer tener control sobre mi vida podría hacer que yo no fuera válida para el tratamiento. ¿Cómo se puede navegar por las turbulencias de la vida si no se lleva el timón? Pero el tono de mi analista era un tono condenatorio. Así, mientras me tumbaba realizando mis asociaciones libres, estaba especialmente atenta a cumplir. Mi deseo era que me considerara analizable.

Mientras yacía en el diván, no podía ver a mi analista. En frente mía en una pared por lo demás vacía, colgaba una gran foto en blanco y negro. Tres niñas pensativas y encantadoras en el periodo de latencia, me observaban con curiosidad petulante, teñida de tristeza. Si giraba mi cabeza a la derecha y dirigía mi mirada hacia abajo, podía ver el pie de mi analista. Muchos aspectos de la forma de vestir y el movimiento de ese pie fueron llenando la pantalla que por lo demás estaba en blanco. Durante varios meses hablé con las niñas y con el pie de mi analista, acompañada por las expresiones de ánimo de mi analista que decía, "Escucho, continúa".

Tras varios meses de obediente charla, fui declarada analizable. Había empezado a encontrarme cómoda con esta forma de estar juntas cuando mi analista interrumpió sus "síes" de apoyo y sus "Mhmh" para ofrecerme una interpretación. Me sentí juzgada y un tanto alarmada al ver que su escucha receptiva sería utilizada para realizar un sabio pronunciamiento sobre mí. Su interpretación me cubrió como una red. Tímidamente comencé a protestar, para escapar de verme envuelta por la fina telaraña de sus palabras. Interrumpió mi protesta verbal ofreciendo otra interpretación. Suavemente, pero con firmeza, me dijo "Me estás viviendo como una crítica y un ataque. Pero yo no soy esa persona. Aun no se quién en tu pasado te trató de esa forma. Es tu pasado con tus otros significativos los que te llevan a verme como si te estuviera criticando y atacando".

¡Catapún! En ese momento entendí: que mi analista (1) era una autoridad sobre lo que realmente me estaba ocurriendo; (2) sabía lo que me ocurría; (3) sabía todo lo que había en 
mi interior; y (4) sabía que lo que me ocurría estaba determinado por mi pasado. Sentí alivio al saber que alguien lo sabía y que lo perturbador estaba dentro de mí. Si estaba en mi interior, Yo lo podía cambiar. Había esperanza.

Las respuestas que ella me daba estaban determinadas por un conjunto de reglas que definen el psicoanálisis. La neutralidad, la abstinencia, el anonimato y las interpretaciones verbales, entre otras formas de estar, determinaron la repuesta de mi analista. La forma de ofrecer sus interpretaciones estaba regada por la calidez y la preocupación por mí. Sin embargo, cualquier tipo de acercamiento físico extra-analítico, o que mi analista compartiera sus experiencias o sentimientos, estaba claramente fuera de los límites del análisis. Éstas posibles respuestas estaban fuera de los límites, no porque mi analista eligiera ser distante o fuera una persona poco expresiva, sino porque un componente crítico para la cura dentro de esta teoría requiere la abstinencia del analista. Freud lo estableció así "el tratamiento se debe de llevar a cabo en la abstinencia... se debe permitir que las necesidades y anhelos del paciente persistan en ella, para que puedan servir como fuerzas que la impulsen a trabajar y realizar cambios." (Freud, 1915, p.164).

Por mi parte, comprendía las reglas, atendía a todas mis sesiones, llegaba y pagaba puntualmente y hablaba de todo aquello que me venía a la mente. No le pedía nada a mi analista fuera de la hora de consulta. Cada vez se me hacía más fácil hablar sin la expectativa de mantener una conversación, siguiendo el discurso intra-psíquico del pensamiento. A medida que mi analista escuchaba e interpretaba, implícitamente me otorgaba el permiso para sentir dentro de la relación y dar expresión verbal a esos sentimientos. Mis sentimientos y los recuerdos asociados se hacían más profundos y abarcaban más. Este proceso empezó a erosionar mi capacidad para mantenerme emocionalmente distante en otras relaciones.

Un viernes por la tarde, en mi cuarto año de análisis, me reuní con mi madre para comer. La saludé e inmediatamente compartí mis últimas y emocionantes noticias. Tras ser madre a tiempo completo y haberme quedado en casa durante 8 años, había decidido volver a estudiar. "Mamá, me han aceptado para el programa Master que yo quería". "Enhorabuena", respondió ella inmediatamente. "Estoy tan orgullosa de ti". A medida que me iba abriendo a sus halagos y celebraciones, ella continuó hablando. La tristeza destelló en su mirada y un pequeño tono de lamento tiñó su voz. Suspiró, "parece que siempre consigues lo que quieres. Eras así también de pequeña. Siempre tenías que ser la mejor". Siguió con sus propios recuerdos, realmente no hablándome a mí, y su lamento se convirtió en resentimiento. "Era tan duro para tus hermanos pequeños". Pausó y entonces posó su mirada sobre mí. "¿Puedes imaginar cómo ha sido para tus hermanos, crecer con una hermana como tú? Les parecía que nunca podrían hacer nada porque tú siempre tenías que 
ser la mejor". Mi habitual habilidad para ni escuchar ni sentir el quemazón de las palabras de mi madre estaba confusamente ausente. Seguí sentada en silencio atónita, y su chorreo injurioso aumentó en intensidad, "No entiendo por qué nunca ayudaste a tus hermanos. Siempre estabas ayudando a los demás. Ofrecías tu tiempo para el voluntariado. Eras una niña que hacías el bien, pero nunca ayudabas a tus propios hermanos. Los demás primero y tu familia después, así eras siempre".

La forma familiar en que mi madre se relacionaba conmigo empezó a tener un impacto poco familiar en mí. Una vida llena de estos comentarios, comentarios que realmente no había escuchado, ahora se agolpaban para ser oídos, todos a la vez. La consiguiente cacofonía era sofocante y me sentí mareada.

Más tarde esa noche, sobre las 7.30 p.m., la aguda voz de mi madre seguía como un eco en mi mente. Sus palabras de ese día continuaban entrometiéndose y acusándome, cada una de ellas un afilado dardo que perforaba y destrozaban mi sentido de mí misma. "Siempre egoísta y dañina". Intenté calmar mi respiración. Intenté retar la racionalidad de las acusaciones de mi madre. Intenté comer. Finalmente localicé a mi analista. Tenía que hablar con ella. Necesitaba que me escuchara y me ayudara a silenciar esas palabras devastadoras. Mi analista devolvió mi llamada y escuchó como años de culpa, vergüenza y angustia hacían que me deshiciera en lágrimas. "¿Había herido de forma irreparable a mis hermanos? ¿Cómo el ser yo misma les había hecho daño a ellos, a ella? ¿Era yo realmente esa zorra egoísta, interesada sólo en mi propio engrandecimiento?

Mi analista escuchó mi creciente pánico e urgencia. Necesitaba su presencia. Su escucha estaba empezando a tener su efecto calmante cuando sentí un cambio en su compasivo silencio. Sentí tensión en su escucha. Quería terminar la llamada. En ese momento yo estaba demasiado desbordada como para cumplir con la demanda implícita de su tenso silencio.

En ese momento me convertí en una paciente difícil. De forma poco característica en mí, continué. Mis palabras seguían saliendo a un paso rápido y sin regulación. Se me perdían los pensamientos. Sentí el esfuerzo de mi respiración y cómo golpeaba mi corazón.

Sentí sus cuidados aun en su falta de expresión, pero se mantenía firme con su teoría. Ella pensaba que responder a mis necesidades en ese momento era una forma de gratificar mis impulsos inconscientes y por tanto de comprometer mi curación. Mi analista finalmente me interrumpió. Me habló de forma pausada, medida y calmada, pero a la vez con un tono autoritario que no permitía ninguna protesta. "Te veré a tu hora habitual el lunes. Promoveremos un cambio de esos sentimientos". 
¿Nuestra hora habitual? ¿En 63 horas? Estaba furiosa. Que mi analista me dejara sola en ese momento era más aterrador y desorganizador que los anteriores castigos que me había propinado mi madre. Entonces, todo sentimiento se desvaneció: apareció el salvavidas de la no-vida. Encontré la calma en el entumecimiento, el entumecimiento necesario para evitar el caos. En el momento que mi analista terminó nuestra llamada telefónica entendí que se esperaba una vez más, como cuando era pequeña, que soportara esos sentimientos insoportables, yo sola. Yo no podía, no estaba dispuesta a tolerar un proceso que requería experimentar el abandono de la persona que esperaba me proporcionara cuidados. También temía que me había convertido en una paciente difícil, tal y como mi analista había pronosticado que podría ocurrir.

Desde la perspectiva teórica de mi analista, ella sentía que necesitaba soportar la tensión de rechazar mi demanda de su presencia. Yo, su paciente difícil estaba demandando una respuesta que ella sabía que comprometería el resultado del tratamiento. Por otro lado, su teoría permitía algunas licencias y provisiones para romper el encuadre analítico, si el paciente estaba en una lucha difícil. Imaginé que éste fue su razonamiento cuando más tarde esa noche me llamó, para preguntar cómo estaba.

Con la tranquilidad que acompaña la determinación de finalizar una relación traumática, le respondí "Estoy bien." Ella preguntó, titubeante, "¿Así que estás mejor? ¿Te veré el lunes?" "Si" respondí de forma seca. Vacilé y añadí, "pero no estaré el lunes. Desde nuestra anterior llamada me he dado cuenta de algunas cosas. Tendrás una carta en tu despacho el lunes." Según iba a colgar, "Eso suena a presagio," respondió rápidamente. Sentí cómo se retaba la certeza protectora de mi decisión de finalizar. Tras una pausa dije, "No es mi intención ser amenazante, simplemente no voy a volver. Dejaré un sobre bajo tu puerta". Entonces ella preguntó, "¿Te reunirías conmigo en mi despacho mañana en vez de mandarme ese escrito?". Emití una débil afirmación, pero mis sentimientos no concordaban con mi tono. Su respuesta disipó mi estado sin vida, y surgieron sentimientos intensos, demasiados intensos. Sorpresa y placer se entremezclaban con miedo. Sentí alivio ya que las 61 horas ahora sólo serían 12, y ella había respondido. Sentí confusión y estaba ansiosa ya que la serenidad de la certeza de mi decisión de dejar el tratamiento se había visto amenazada.

Mientras conducía hacia la consulta de mi analista el sábado por la mañana, mentalmente ensayaba mis palabras de finalización para estar preparada contra cualquier protesta persuasiva que imaginé podría ofrecerme. Según entré en su despacho, me pidió que habláramos cara a cara. Me explicó que yo estaba experimentando confusión y que eso estaba interfiriendo con mi tratamiento. Que la había confundido con mi madre. Pacientemente explicó que según habíamos trabajado en análisis era posible que yo la 
experimentara como si ella fuera mi madre, pero que era crítico que yo me mantuviera aferrada a la realidad. Me dijo, "No soy tu madre. Soy tu analista. Debemos realizar varias sesiones cara a cara para resolver la transferencia psicótica".

¡Catapún! Otra vez. Pensé que estaba enfadada con ella. Era ella la que había rechazado estar conmigo, cuando la necesité. Y en lugar de eso, ¿soy una psicótica? Estaba atónita y más que perpleja. Se me había olvidado lo que había aprendido de ella al principio del análisis. Es todo yo, y dentro de mí, y ella sabía lo que había dentro de mí. Tras algunas sesiones en las que nos sentamos cara a cara para diluir la intensidad de mi transferencia, me calmé. De nuevo me tumbé para comprender más, y reanudar mi experiencia "como si" con mi analista. Su paciente difícil se había vuelto de nuevo complaciente.

En ese momento, en una noche de viernes de hace muchos años, me volví una paciente difícil. No era difícil porque era viernes por la noche, tras un largo día, o una larga semana, y no era difícil porque demandaba una respuesta emocional y personal; principalmente era difícil porque la respuesta particular que yo necesitaba era una que la teoría de mi analista consideraba un impedimento para mi proceso curativo.

Aunque hoy diría que realmente estaba enfadada con ella por no responderme en un momento de crisis, añadiré que el que me viera el sábado me ofreció la respuesta de cura requerida, a pesar de lo inaceptable para mí del contenido verbal de su interpretación y su teoría explicativa.

Sin embargo, años después, me trasladé del diván analítico al sillón del analista. Como analista empecé a cuestionar la objetivación y veracidad científica de la teoría de mi anterior analista, y por tanto cómo estaba formada su técnica.

En mi segundo relato analítico, la teoría de la especificidad subyace a mi relación terapéutica con mi paciente.

\section{La práctica que prioriza la especificidad del proceso}

El transcurso de este análisis ${ }^{2}$ ha estado marcado por cambios rápidos de transferencia positiva a negativa, extremos y aparentemente discontinuos. En la transferencia positiva, mi paciente Beth me experimentaba como toda bondadosa y poderosa. Me llamaba su "Jesús con piel". En otras ocasiones, Beth me percibía como una seductora sádica que creaba momentos íntimos de amor para poder realzar mi poder para herirla. $Y$ en otras ocasiones yo era experimentada como un terapeuta negligente, que le daba la espalda justo en los momentos críticos en los que necesitaba ser reconfortada o protegida. La percepción que Beth tenía de mi podía cambiar rápidamente desde sentirse segura conmigo a sentirse o bien 
abandonada o incluso que yo la maltrataba. Y necesito añadir que estos cambios podían ocurrir sin conocimiento por mi parte de algún hecho concreto que lo precipitara. Por mi parte, pude haber sentido tan sólo una ligera alteración en mi postura física o expresión o calidez en el tono o contenido de mi discurso.

Este relato analítico comienza a finales del tercer año de análisis: Había habido tensión entre Beth y yo desde quizás los primeros días de nuestro trabajo juntas. Esta tensión se había mantenido en los límites de nuestra relación. Lo sentíamos y huíamos de ello, no llegando nunca a reconocerlo o nombrarlo. Sin embargo, en esta sesión Beth estaba visiblemente alterada cuando entró en mi despacho.

Beth se recostó sobre el diván en silencio. Su frustración y rabia eran palpables, como también lo era mi creciente tensión y confusión. En silencio revisé mentalmente nuestra última sesión y no recordaba nada que pudiera explicar sus sentimientos, algo que me ayudara a encontrar el significado de su ira acusatoria. Finalmente habló, demandando "¿Lo harás o no lo harás... sostenerme3?" Para mí, la tensión relacional de este momento se cristalizó, no por la cruda demanda de Beth de ser sostenida, sino por la vulnerabilidad de su angustiosa súplica, "Necesito que me des el sostén y la caricia tranquilizante. Esto es demasiado para mí, sentarme en tu presencia, la presencia de los cuidados. Realmente necesito el tacto físico. Necesito ser sostenida".

Supongo que mis expresiones corporales y faciales contestaron a su pregunta con una negativa antes de que siquiera pudiera empezar a pensar en su demanda. En general en mi vida personal, no soy una persona muy dada a los abrazos y gestos físicos. Estoy dispuesta a tocar y sostener a mis seres queridos para reconfortarles, reasegurarlos o transmitirles amor. Durante un rato. Pero no estoy cómoda con sostener o ser sostenida de manera duradera.

Al decidir cómo responderle a Beth, no quería decir simplemente "No." En lugar de decir "No", o quizás "No lo se", esperaba quedarme con sus sentimientos y transmitir mi comprensión, una comprensión que quizás pudiera ofrecerle la experiencia de ser sostenida por mí. "Al sentir tu amor por mí y el mío por ti, los viejos sentimientos del bebe que no fue sostenido ni acariciado, emergen junto con ellos. Tu sufrimiento hoy de esta privación temprana sólo puede aliviarse a través de mi sostén físico. ¿Sirve de ayuda cuando yo lo comprendo e intento mantener la conexión con esa pequeña, conectada con nuestros intercambios diarios de mensajes de voz?"

Beth se aleja de mí, de mi "no" implícito. Me quedo callada. Puedo sentir la intensidad de su sufrimiento, un dolor que se ha ido intensificando a lo largo de los últimos meses, un dolor que no remite al final de nuestras sesiones. Siento también la dolorosa confusión que su 
necesidad de mi crea en ella. La adulta madura, inteligente y competente ansía ser acariciada y mecida como si fuera una niña. Lucho con el dilema, simultáneamente deseando responder y distanciarme de la súplica de Beth.

Sin una respuesta formal prescrita como se encuentra en la mayoría de las teorías estructuradas, me encuentro sola para implicarme en un proceso analítico único con este paciente. Debo examinar mis propias capacidades y limitaciones para responder ante la demanda de mi paciente, y explorar las implicaciones terapéuticas de mi respuesta. Debo satisfacer las necesidades que siente mi paciente, que para mí resultan incómodas, o aguantar la decepción, ira y dolor en mi paciente al sentir que no puedo ofrecer la respuesta deseada, todo dentro del contexto de cómo mis respuestas puedan ser o no terapéuticas para mi paciente. Sin una respuesta teórica predeterminada o tan siquiera una guía, estoy convocada a analizar y valorar la demanda que me hace mi paciente dentro del contexto único y la relación que es siempre emergente entre nosotras.

Finalmente, Beth responde. "Tu respuesta hace que estos sentimientos sean aún más intensos, pero también más manejables. Puedo hablar sobre esto hasta el infinito, y decir lo mismo siempre. Pero no cambia la necesidad de ser sostenida por ti. Quiero sentirte. Necesito saciar mi deseo de ser sostenida. Estoy llorando y llorando por ser alimentada y tú me ofreces tus palabras. Tus palabras no me tocan".

Esta sesión inició muchas más sesiones encaminadas inevitablemente hacia su demanda insistente de ser sostenida y acariciada por mí. Mi comprensión de su estado agonizante se hacía más profunda a medida que animaba a Beth a compartir sus sentimientos, y sus recuerdos. Beth nació de una madre que se había sentido demasiado desbordada y deprimida como para responder a Beth. Su madre relata hoy cómo Beth, de bebé, había sido una bebé tan buena, contenta la mayor parte del día, sola en su corralito. Beth recuerda como anhelaba ser sostenida, incluso rodeándose a si misma con sus pequeños bracitos, imaginando que eran los de su madre. Recordaba muchas noches de su infancia en que abrazaba la pared de escayola al lado de su cama. Tras un rato la pared absorbía y mantenía su calor, y ella podía imaginar que estaba acurrucada con su madre.

Cuando Beth tenía 2 años, el trastorno de ansiedad de su padre le incapacitó para el trabajo y se le dio de baja. Al volver su madre a trabajar, Beth se quedó bajo los cuidados de su padre mentalmente enfermo. Su padre la atraía hacia unos deliciosos momentos de intimidad, para sobresaltarla, asustarla o incluso herirla. Una escena modelo de esto (Lichtenberg, 2005), está capturada en su recuerdo de una fría noche de invierno cuando tenía 4 años. Su padre la despertó del sueño para invitarla "Ven. Hay magia fuera". La arropó con su gran chaquetón, de los pies a la cabeza. La llevó en brazos fuera. Le susurró, "Y ahora la función 
de magia", mientras él levantó la manga de la chaqueta como un telescopio. Desde el interior de la cálida chaqueta alzó su mirada y mágicamente apareció un cielo lleno de estrellas. Recuerda el entusiasmo repentino y compartido, mientras su padre sigilosamente echó un vaso de agua gélida por la manga. Ella salió corriendo, Ilorando, mojada y fría al son de la risa satisfecha. Los demás en la familia la reñían por no saber encajar una "broma". Su madre no sólo era incapaz de responder emocionalmente a su hija, sino que tampoco podía protegerla a Beth de su padre.

Sin embargo, mi comprensión y nuestra comprensión más profunda de sus sentimientos, a través de la revelación de estos recuerdos, no aminoraba su intenso y tormentoso deseo de descansar entre mis brazos. Continuamos explorando su deseo y elaborar los posibles significados y la génesis de esta necesidad y deseo. Trabajamos de esta forma muchos meses, pero con cada nueva comprensión o recuerdo, volvía a su necesidad concreta de ser sostenida. Empezó a estar desesperada. Empezó a hacer planes para dejar el análisis y encontrar un terapeuta que la sostuviera durante las sesiones. Yo sentía un continuo estrés, y estaba normalmente preocupada de cómo y/o cuándo Beth y yo encontraríamos una forma de abordar su tan intensamente sentida necesidad, una necesidad que yo no podía realmente satisfacer.

Si este análisis se hubiera realizado dentro de una teoría de la estructura, como la teoría clásica, hubiera tenido una guía teórica, incluso una respuesta. Freud ofrece la siguiente respuesta a mi dilema: "El tratamiento analítico debe realizarse, dentro de lo posible, bajo la privación... en un estado de abstinencia" (1919, 162). El analista debe asegurar que "se deja al paciente con una abundancia de deseos insatisfechos" (1919, 164). En otras palabras, Freud prescribía la abstinencia. La abstinencia era la actitud presuntiva, y cualquier desviación de la misma, constituía una "provisión". Una provisión (como tocar, y ni qué se diga sostener a mi paciente) era cualquier cosa menos una explicación interpretativa, y estaba proscrito. Según esta teoría, una provisión gratificaría los deseos inconscientes libidinales de mi paciente, privándola de la oportunidad de hacerles conscientes. La cura en esta teoría ocurre al hacer que los empeños libidinales inconscientes sean conscientes y se interpreten. Con esta nueva consciencia, se posibilita la renuncia a los deseos infantiles y se reemplazan por deseos y objetivos más maduros.

La prohibición de tocar no se ciñe a la teoría clásica. En la mayoría de las teorías psicoanalíticas tradicionales el tocar está proscrito, ni qué decir sostener, como algo que van en detrimento de la cura del paciente. Sin embargo, yo trabajo desde la teoría de procesos, la Teoría de la Especificidad. Cualquier clínico que utilice esta teoría puede o no seguir la conclusión de la teoría (de hecho, Freud mismo no siempre seguía los dictados de sus propios 
escritos sobre la técnica), pero a pesar de cómo un clínico en particular pueda utilizar la teoría, aquí me preocupa la operación de la teoría en sí misma. La teoría de la especificidad no prohíbe tocar (ni ninguna otra respuesta), a no ser que sea ilegal o esté oficialmente proscrita por la organización profesional de pertenencia, sino que dicta que el analista se implique con el paciente para averiguar si esa demanda es terapéutica para el paciente y posible para el analista.

Mi paciente demandaba y creía que su cura requería mi caricia cariñosa y sostenida. Sin embargo, mi capacidad para ofrecer esa respuesta era limitada, y se quedaba corta para el tipo de sostén que mi paciente ansiaba. Para mí, el sostener no tiene un punto final natural o que se pueda acordar. Me imaginaba que podría empezar a sentirme ansiosa con el tiempo, por la contención física o emocional que el sostener me exigiría, que ella sentiría y que posiblemente podría interpretar como rechazo. Si decidíamos que la sostendría a lo largo de la sesión, imaginaba discusiones incomodas para determinar el cuándo y la duración del abrazo acogedor. ¿O se convertiría en una ritual, una forma esperada de cómo estaríamos juntas en la sesión? Con un abrazo prolongado me imaginaba extremidades entumeciéndose y comezón que no podría rascar. ¿Cómo hablaríamos de no estar abrazadas en una sesión, y qué significados presentes e históricos se le daría a tal discusión?

Más aún, y más significativo dada la naturaleza de nuestra relación a lo largo del curso del análisis, podría existir el peligro de que con el prolongado sostén ella empezara a sentir que yo la estaba explotando o abusando de ella. Dos personas experimentan y comparten sentimientos intensos a través del sostén físico, y esto puede hacer que sea más difícil identificar o hablar de ello. Sus significados podrían ser implícitos, intensos y rápidamente cambiantes. ¿Quién sujeta a quién, quién necesita ser sostenido, necesito yo que ella me necesite sostenerla? A lo largo de nuestra relación Beth me había experimentado como abusiva y que la explotaba cuando sentía que aumentaba la intimidad. No era capaz de explorar estas creencias como (parte de) su experiencia subjetiva, sino como pruebas concretas de mis malévolas intenciones.

Estaba confrontada a discernir la respuesta o respuestas que ofrecieran experiencias de cura para mi paciente y que yo sintiera con la voluntad y capacidad de proveer. Empezó a vivir mi negación como algo sádico, que yo desde el comienzo había diseñado nuestras interacciones para crear ésta intensa necesidad de mi para poder disfrutar de mi poder mediante la privación. O de forma alternativa, cuando ella me vivía como menos mala, sentía que mi negación estaba motivada por mi deseo inconsciente de ella: era yo la que la necesitaba desesperadamente, que necesitaba que dependiera de mí. Razonaba que, si la sostenía, 
estaría más sana por lo que no necesitaría la terapia. Entonces yo, que tan desesperadamente la necesitaba, la perdería.

A medida que continuaba ofreciendo a mi paciente mi comprensión y que sufría con ella, y aguantaba su resentimiento y su ira, encontré una manta. Era del tamaño, peso y textura que envolvería a un adulto tal y como un progenitor haría al sostener a su hijo. Por un lado era de un satén liso que ofrecía una experiencia táctil sensual y el reverso era de un punto sintético que ofrecía calor, profundidad y cedía al tacto, similar al tacto de un cuerpo humano. Pensé que era posible que la manta, si se la daba yo, podría ofrecerle la experiencia de sostén que necesitaba.

Me preguntaba si debía ofrecer esta respuesta concreta a su demanda. ¿Debería de haber concluido que mi dificultad para ofrecer un acogimiento sostenido le imponía una limitación debilitante en la posibilidad terapéutica de nuestro trabajo, y haberle encontrado otro terapeuta que trabajara de otra forma distinta a la mía? ¿O debería seguir intentando responder, ahora de esta forma? ¿Acaso el confort de la manta calmaría de tal forma las experiencias que daban lugar al incesante dolor, que haría por tanto que ella ya no estuviera disponible para el análisis, creando algún tipo de dependencia de mí, discapacitante, buscando el alivio continuo? ¿O acaso ofrecería una respuesta que le haría capaz de experimentar un mundo relacional en el que los seres queridos responden al dolor sin el deseo de herir o de explotarla? ¿O podría ser vivido tanto como una respuesta de cura y por el momento un nivel necesario de dependencia? Éstas eran las principales preguntas con las que luchaba, al considerar los posibles efectos terapéuticos - o no - de esta respuesta especifica - y que yo sentía que si podría ofrecerle a Beth.

Al presentarle la manta a Beth en una sesión, le pregunté, "¿Cómo te sentirías si yo te diera esta manta a ti?" Beth se quedó callada, no respondió y no se implicó conmigo (en ese tema). Al llegar el final de la sesión, sin mediar palabra cogió la manta (y se la llevó). La mañana siguiente me desperté con un mensaje de voz: "Tu eres analista. Así que tú me puedes analizar, eso es cosa tuya. Pero quiero que sepas que la manta... tiene la textura más gozosa y suave. Tú estabas conmigo anoche. Abracé la manta con fuerza y me reconfortó. Sin ataques de pánico. Tu pensaste en esta idea y está funcionando de maravilla" c.

Beth pudo utilizar la manta de otras maneras para regular nuestra relación. Cuando estaba enfadada o decepcionada conmigo, era capaz de utilizar la manta para darle más expresión a sus emociones. La mañana tras una sesión tormentosa, Beth me dejó este mensaje de voz: "Con la manta he mejorado mis mecanismos para reconfortarme porque te tengo. Pero ahora veo que ayuda porque también puedo conseguir lo que quiero de ti. Tú no estás en esa manta por lo tanto soy más libre para hacer lo que me venga en gana con ella. Es más 
seguro que tenerte a ti en la realidad. Está llena de vida, pero a la vez sin vida. No confío. Estoy dispuesta a intentarlo, pero yo sé que necesito algunas cosas profundas y no me fío de dejar que te acerques".

Y entonces la manta tuvo un sorprendente efecto negativo. La manta encajaba tan perfectamente con su necesidad y deseo que intensificó su creencia de que yo conocía perfectamente sus pensamientos, creencias y emociones. "Es como si fueras Dios y me conocieras completamente". Esta creencia en mi omnisciencia constreñía nuestra relación. Ahora, si actuaba en formas que le eran injuriosas, sólo podía creer que lo hacía intencionadamente, ya que ella sabía que yo conocía perfectamente lo que ella quería o esperaba. Más adelante, durante nuestras sesiones, si le preguntaba cómo se sentía sobre algo, se enfurecía, ya que creía que yo sabía cómo se sentía. No había ninguna razón para preguntar, ya que yo lo conocía todo, si no era para disfrutar de mi poder para herir.

Finalmente, la provisión de la manta si mejoró la confianza de Beth en nuestra relación, y le ofreció la experiencia que parecía contribuir a una expansión de su capacidad para tolerar emociones y recuerdos, y luego beneficiarse de las interpretaciones verbales. Sin embargo, mi experiencia en este análisis no apoya ni la oferta de la manta, ni este tipo especial de manta como una respuesta prescrita ni tan siquiera recomendable. Es posible que nunca más vuelva a utilizar una manta de esta forma. Este análisis tampoco apoya la teoría de permitir parámetros (Eissler, 1953) que luego permitan interpretaciones verbales más capaces de mejorar. Quizás mi comprensión, cómo se demostró con la ofrenda de la manta, fue esencialmente transformativa para este paciente, aún ausente de futuras interpretaciones.

En una sesión, meses después de que la manta hubiera asumido su complejo lugar en nuestra relación, Beth compartió, "El rabioso y aislado lugar en que el que he estado. Lo sentía como si estuviera luchando contra el mundo y ahora veo que soy yo. Por mi trauma. Mi padre era un hombre enfermo. Era maltratador y sexualmente retorcido, y yo era, soy, sensible, sensual y emotiva y estuve bajo sus cuidados a tiempo completo. Físicamente no tuve consuelo. Yo podía gritar. Yo podía llorar. Mama estaba tensa y nerviosa. No hubo un sostén calmante. Lo que sé sobre ser reconfortada, lo he aprendido a través tuyo. Ahora sé que un bebé tiene sus necesidades. $Y$ esas necesidades deben ser atendidas y no hay vergüenza. Es tan sencillo como que un bebé necesita ser sujetado y reconfortado".

Estas dos historias ejemplifican algunos contrastes clínicos y las consecuencias diferenciadoras entre la utilización de la teoría de la especificidad como proceso, en contraste con una teoría de estructura - como el psicoanálisis clásico - como tema que veremos en más profundidad en el capítulo $7^{4}$. En el primer ejemplo, la teoría del analista 
prescribía determinadas formas para responder y no responder a su analizado. La constricción de su teoría, que podríamos argumentar era una parte central de quien ella era profesionalmente - determinaba su respuesta y daba forma íntimamente a la naturaleza de la relación entre analizado y analista. En el segundo ejemplo con una teoría que explícitamente amplía el rango de las respuestas terapéuticas no-prescriptivas, teoría que juega un papel diferente en el proceso terapéutico e influye en la posibilidad terapéutica de forma fundamentalmente distinta. Trae a primer plano el examen de la manera particular que este analista puede o no ser capaz de trabajar de forma óptima con este paciente en particular. Es decir, trabajar con esta teoría requiere que el analista examine las posibles limitaciones en su capacidad para responder de forma terapéutica a este paciente en particular. En el proceso ella estaba descubriendo, cómo podría estar, terapéuticamente, con este paciente. También estaba descubriendo de forma creativa una manera de conectar con ella que pudiera manejar, a un nivel simbólico arcaico, y que funcionara para su paciente. Sus propias limitaciones y capacidades vis-á-vis éste paciente estaban en el centro de su examen, y no los estándares definidos teóricamente, o una teoría estructuralmente definida, contra la cual evaluar si el paciente era tratable (ver el capítulo $8^{5}$ donde estudiamos en mayor profundidad la cuestión de la "analizabilidad" desde la perspectiva de la teoría de la especificidad).

La práctica basada en la teoría de la especificidad implica centralmente un proceso de descubrimiento de respuestas que pueden ser efectivas terapéuticamente para un paciente particular, pero sin el uso de unas prescripciones o guías proscriptivas, aunque surjan hipótesis de teorías tradicionales de la estructura, que sean de utilidad. Cuando somos capaces de captar lo único y especifico de cada encuentro terapéutico, podemos implicarnos continuamente en el momento para determinar cuál es la respuesta terapéutica necesaria, y qué nos es posible ofrecer para cada ocasión.

\section{REFERENCIAS}

Bacal, H. (Ed). (1998). Optimal Responsiveness. How Therapist heal their patients. Lanham, Maryland: Jason Aronson.

Bacal, H. with Carlton, L. (2011). The Power of Specificity in Psychotherapy. When therapy works and when it doesn't. Lanham, Maryland: Jason Aronson.

Eissler, K. (1953). The effect of the structure of the ego on psychoanalytic technique, J. Amer. Psychoanalytic Assoc., 1: 104-143.

Freud, S. (1915). Observations on transference-love (Further recommendations on the technique of Psycho-analysis III), SE, XII 
Freud, S. (1919). Lines of advance in psycho-analytic therapy. S.E. XVII

Lichtenberg, J. (2005). Craft and Spirit. Hillsdale, NJ: The Analytic Press.

Original recibido con fecha: 3-4-2017 Revisado: 6-5-2017 Aceptado: 30/06/2017

NOTAS:

${ }^{1}$ Lucyann Carlton

${ }^{2}$ Este caso se presentó como parte de un trabajo en co-autoría de Howard Bacal y Lucyann Carlton, titulado "La teoría de la especificidad: Descubrir la eficacia terapéutica en el proceso de la especificidad", en los encuentros de invierno de la American Psychoanalytic Association, 20 de enero de 2008

${ }_{3}^{3} \mathrm{~N}$.de T.: Hold/Holding refiere aquí la actitud de acogimiento que se manifiesta mediante un abrazo, abrir los brazos para que el otro pueda ser acogido en un momento de sufrimiento y angustia.

${ }_{4}^{4}$ Capítulo 7 del libro al que pertenece este fragmento del capítulo 3 (ver nota al pie inicial: i)

${ }_{5}^{5}$ Capítulo 8 del libro al que pertenece este fragmento del capítulo 3 (ver nota al pie inicial: i) 